\title{
Construction of Blended Learning Based on Moodle
}

\author{
Cizhen Zhang, Jiaming Zhonga \\ Xiangnan University, 423000 Chenzhou Hunan, China
}

\begin{abstract}
In recent decade, with the rapid development of network teaching, people's learning style is developing from single classroom learning to the blended learning with the combination of classroom teaching and online learning. Nowadays, blended learning has become a hot topic of teaching reform in colleges and universities. Combing the general model of blended learning and teaching functions of Moodle platform, the author puts forward blended learning based on Moodle platform, to enhance learning efficiency.
\end{abstract}

\section{Introduction}

The development of network and information technology has changed the environment and conditions of university teaching to great extent, and many universities have purchased advanced multi-media classrooms, so they possess favorable network systems and other digital learning environment. These universities adopt a brandnew network learning, which is formed by multi-media network learning resources, online learning community, and network technology platform, to perform E-learning (online learning or network learning). Therefore, blended learning, which is combined by traditional classroom learning and E-learning, has become a new orientation of teaching reform in colleges and universities.

Blended learning combines the advantages of network teaching and face-to-face teaching, to obtain better teaching effect, so it is better than single teaching style. Blended learning first needs a virtual learning environment. As a free network teaching platform, Moodle features some merits in supporting blended learning that are not possessed by other commercial network learning platforms, and it is being widely promoted and applied by many middle schools, colleges, and universities.

\section{Blended Learning}

With regard to the meaning of blended learning, according to the explanation of American Learning circuits, blended learning is regarded as a learning style that combines online learning and face-to-face learning.

Professor Li Kedong and Professor He Kekang are representative scholars in China. Professor Li maintains that "The main thought of blended learning is to integrate face-to-face teaching and online learning, to reduce cost and increase benefits."

Although there are different opinions among foreign and domestic scholars, viewing from the perspective of teaching and learning, blended learning is to well combine the advantages of face-to-face classroom learning and E-learning. In nature, blended learning is a new learning style or learning concept, which can better combine classroom learning and online learning. In teaching, teachers may select different styles in accordance with their teaching objectives and teaching contents, but their final goal is to improve students' learning efficiency and learning effect. Some contents need face-to-face learning, some adopt online learning, but some combine these two methods. These teaching and learning methods can effectively make up the shortcomings of single learning style, offer various ways of exchange between teachers and students, strengthen the interaction between students, as well as teachers and students, and improve students' initiative, agency, and activity. In this way, it can remedy the defects of face-toface learning in this aspect, and it is good for the expansion of space and time. In other words, it has certain influence on enhancing the teaching quality and teaching level.

\section{TEACHING FUNCTIONS OF MOODLE PLATFORM}

Moodle is a course management system developed by Australian Martin Dougiamas based on the education theory of social constructivism, which is free open source software, as well as a network course development platform and information learning management system. This system can help teachers create and manage online courses in large number, and it is one of the most popular network course management systems in the world. Since 2008, China has begun to promote Moodle course management system, and there have been more and more schools and districts to apply it to course reform and teaching activities of primary and secondary schools.

a Corresponding author: jmzhongcn@163.com 
Teaching functions of Moodle mainly include website management, learning management, and course management (Figure 1). The major reason of utilizing Moodle is that it can conduct all kinds of teaching activities in course management, such as course management, homework module, voting module, forum module, test module, resource module, questionnaire module, and interaction module.

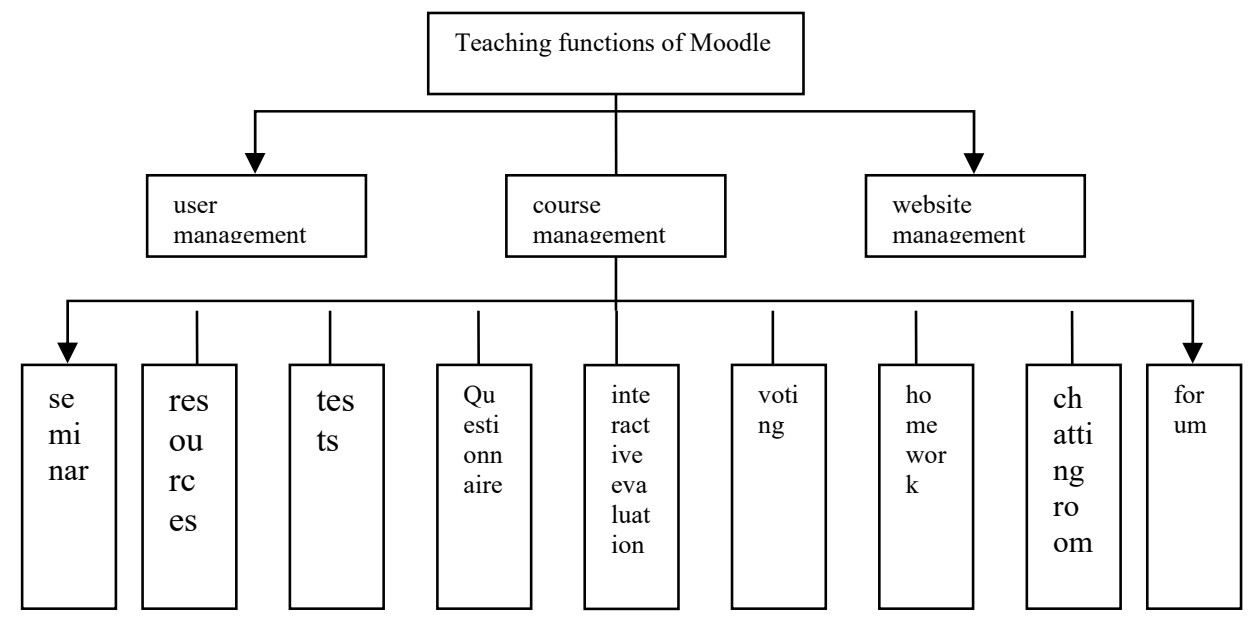

Figure 1. Teaching Functions of Moodle

The author constructs a digital learning platform for students by making use of Moodle, and creates a virtual learning environment in line with demands, to help students with different levels to conduct independent study or cooperative research-based learning by using resources on the platform and in accordance with their actual situations. Through Moodle learning platform, teachers can achieve teaching in different places in certain area. In the teaching activities of research-based learning in particular, in Moodle learning platform, teachers can take part in the real-time or non real-time exchange among students, guide students to learn, and help students solve difficulties in learning. Moodle learning platform can also be used as a tool for online group cooperative learning. Blogs or forums may establish learning area for each group, to help them conduct group exchange in chatting rooms or forums, which is greatly convenient for students to cooperate and share knowledge. What's more, students can understand the learning progress of other groups in each forum, finding out the research contents and advantages of other people. Through contrast and learning, students can summarize and reflect their disadvantages, to adjust their methods and strategies of solving problems. Therefore, it can arouse students' learning enthusiasm in the competition among groups. As a whole, Moodle can provide conditions for the blended learning of university students.

\section{CONSTRUCTION OF BLENDED LEARNING MODEL BASED ON MOODLE}

In blended learning model, most learning is completed in traditional classroom teaching, which mainly has the following contradictions: selecting traditional classroom learning or online learning, time distribution between online learning and classroom learning, and selecting contents suitable for classroom learning and online learning respectively. To solve the major conflict of blended learning, we must seek a intersection point between classroom learning and online learning. Therefore, selecting a suitable network teaching management platform is the key to solve this problem. Because Moodle platform is a free course management system, with low application cost and convenient application, and it can organize various teaching styles in teaching, it has offered a stable support for the study on blended learning and the construction of online learning environment. Besides, Moodle can well combine online learning and classroom learning by means of blended strategies. The blended framework based on Moodle learning platform is as follows:

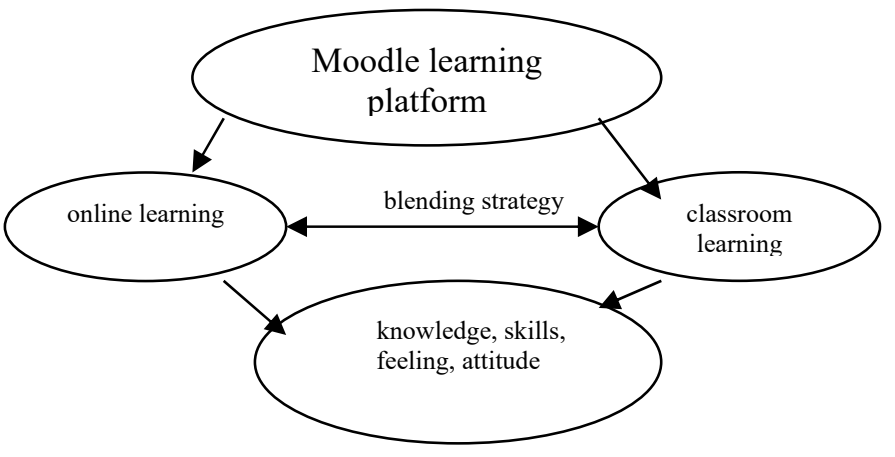

Figure 2. Blended Framework

The design of Moodle "resource+ activity" is different from duck-stuffing and cramming teaching under traditional education system. It can not only provide learners with an environment to learn independently and record freely by making use of resources, but also offer a platform for students to make discussion, interaction, and evaluation to take part in group learning. Teachers can collect students' participation degree, provide resources, and raise related questions for students to discuss. Meanwhile, they require students to submit their homework or group results. During the process, teachers will lead and join the whole activity, while students may upload their resources, to serve for the generation of 
resources. Teachers will continuously guide students to learn and improve their teaching strategies through following learning activities. The online learning environment created by Moodle is helping students to change from original cramming education to creative learning based on knowledge interpretation.

Moodle platform combines teaching activities with course resources, to manage students' learning process, evaluate the activity results, as well as save and record students' learning process and results. In course design before teaching, teachers will design corresponding teaching activities on Moodle platform, and provide resources for students to take part in teaching activities actively. Moodle platform has various kinds of interactive environment. For instance, chatting module supports neat and synchronous text interactive chatting window, as well as various types of file format. It has various types of forum, so that teachers can set corresponding parameters or force students to subscribe posts in the forum. On the other hand, students can upload homework or resources to servers, and clearly submit their practice record. Then, teachers will give a fair evaluation to students' homework. Meanwhile, the uploaded resources can be shared, and new resources will be supplied. Therefore, it can greatly enhance learners' activity, expand learners' contact surface, and enrich course resources.

The interactive evaluation on Moodle platform can implement diversified teaching evaluation. For example, this platform records each student's learning process, to conduct process evaluation and portfolio evaluation; it conducts summarized evaluation and collective evaluation for the final result; peer evaluation and teacher's evaluation for each member. The combination of various evaluation methods in the process can help students solve the problems of learning, and evaluate students in a more comprehensive way. Combining the general model of blended learning and teaching functions of Moodle, the blended learning model based on Moodle is as follows:

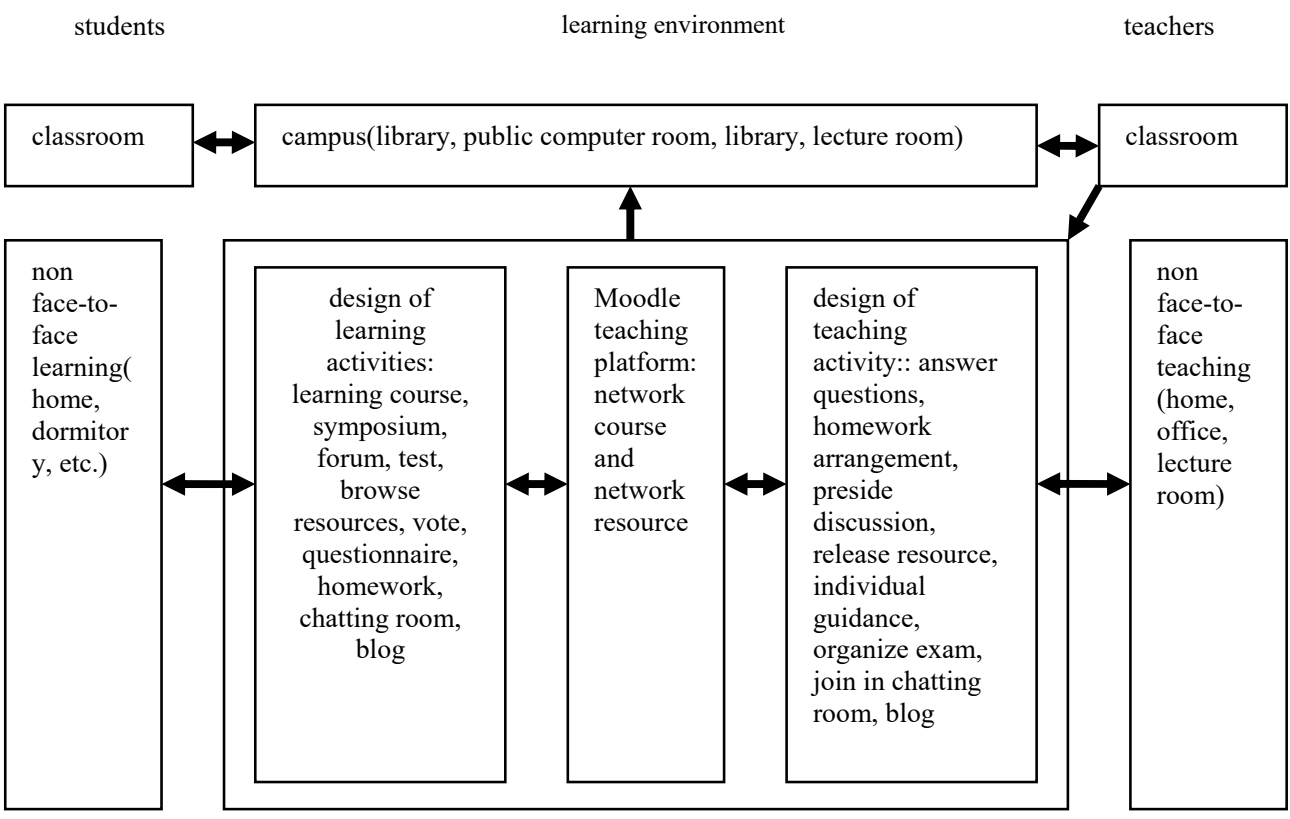

Figure 3. Blended Learning Model Based on Moodle

According to the blended learning model and related theories, the procedures of conducting blended learning by making use of Moodle platform are as follows:

Before teaching activities, teachers will create a network management platform for their courses after making a teaching design program in accordance with their teaching contents. Although it can increase students' workload during the preparation before class, it has large number of quality courses and network courses for reference now. Meanwhile, they can utilize the given learning websites, to add some appropriate contents to their network courses. Teachers will upload network teaching resources that can be utilized or consulted, including content presentation, explained education resources, exam questions and test papers for teaching evaluation, bibliographic index for expanding learning contents, as well as diversified or compounded multimedia teaching courseware, such as video, audio, animation, figures, and pictures. These resources, as referential and unloading resources for students, can guarantee students' learning activities. Besides, teachers can design some teaching activities through referring to designed course objectives, course contents, and presentation types according to the teaching progress. For example, in different chapters, they can design symposiums, research questions, group tasks, group discussion, common questions, self-test, or homework.

- When teaching begins, teachers will organize all the students to register in Moodle and become users of this course. Students can browse corresponding teaching contents before class as preview. Before teaching a certain content, teachers should provide the learning resources of this part on Moodle platform, put forward related learning tasks, set up discussion and assignments for students, to offer a favorable online learning environment for students. Then, they will adopt face-toface teaching method to give lessons in class, and help students understand related learning objectives after each class. Teachers will also raise some questions to be discussed for online learning. 
After face-to-face teaching, students will take online learning in line with their needs. First, students will learn independently by making use of the teaching contents and resources provided by teachers, to learn the course more comprehensively. Then, students will conduct online research learning with group cooperation on Moodle platform through related functions. In this way, students will complete the learning tasks assigned by teachers through cooperation, and upload their results on Moodle platform. During students' learning period, teachers will help, evaluate, and guide students along the whole process, analyze students' tasks at each stage, lead and help them solve problems, and summarize their homework.

After research-based teaching activities, students will summarize their learning thorough homework, discussion, and test individually or by group, write blogs about learning, summarize their problems and methods during the learning process, and conduct interactive evaluation and self-evaluation for their group. Students will summarize their learning experience after learning each topic, to make preparation for the next stage. Teachers will also make summarized evaluation for students at each stage, and reflect their own teaching. They will summarize the experience of blended teaching in Moodle platform, continuously improve teaching, explore new teaching model, and offer better methods for next stage.

\section{CONCLUSIONS}

Modern education advocates different teaching strategies for different subjects, and advocates "leading-dominant" teaching style, to give play to the leading role of teachers and dominant role of students to the largest extent. However, blended learning based on Moodle platform emphasizes "learning", which embodies the dominant role of students, while teachers only play the role of leaders, to guide students' learning. As more and more people are attaching importance to blended learning and Moodle network teaching platform is being improved steadily, we believe the blended learning based on Moodle platform will unnecessarily play a better role in all kinds of schools.

\section{Acknowledgement}

Thanks for being supported by Hunan Provincial Natural Science Foundation of China(No.2018JJ2371), The 13th Five-Year" educational planning project in Hunan province, "Study on Construction and Development of Mobile Learning Model for University Students in Bigdata" (XJK17CXX007).

\section{References}

1. C.P. Xiong, D. Wu, China Educational Technology, 11(2006)

2. H.F. Chen, B. Luo, The Chinese Journal of ICT in Education, 3(2007)
3. N. Xu, Information Technology Education, 7(2007)

4. Z.J. Gao, Y.D. Fan, Business Economy, 8(2010)

5. S.Q. Yu, Q.L. Lu, China University Teaching, 10(2005) 